\title{
Examining the Effectiveness of Pre-reading Strategies on Saudi EFL College Students' Reading Comprehension
}

\author{
Hana S. S. Al Rasheed ${ }^{1}$ \\ ${ }^{1}$ College of Education, King Saud University, Riyadh, Saudi Arabia \\ Correspondence: Hana S. S. Al Rasheed, College of Education, King Saud University, Riyadh, Saudi Arabia. \\ E-mail: hana.1430@hotmail.com
}

Received: July 14, 2014 Accepted: September 10, 2014 Online Published: October 23, 2014

doi:10.5539/elt.v7n11p79 URL: http://dx.doi.org/10.5539/elt.v7n11p79

\begin{abstract}
Reading comprehension is a key issue in learning English as a foreign language, and it is critical that teachers utilize pre-reading strategies in reading classes in order to help students enhance their comprehension. The present study investigates the effectiveness of two pre-reading strategies on EFL students' performance in reading comprehension. A group of 46 students from King Saud University, Preparatory Year, participated in this study. A quasi-experimental design was used, with 23 students being assigned to the first experimental group that received one pre-reading strategy (vocabulary pre-teaching) while the remaining 23 students received another pre-reading strategy (pre-questioning). Students in both groups were asked first to perform the pre-reading strategy, read a passage, and then answer comprehension questions. Results indicated that there were no statistically significant differences between the two groups. Some implications have been drawn for EFL teachers and material designers.
\end{abstract}

Keywords: EFL teaching reading, pre-reading strategies, pre-questioning, reading comprehension, schema theory, vocabulary pre-teaching

\section{Introduction}

Reading skills are a receptive skill in which meaning is extracted from the discourse (Harmer, 2007). Thus, translating written symbols into corresponding sounds is not reading; rather, it is decoding (Ur, 2007). Exposure to easily understood language through reading texts or listening tracks is considered to be a condition for learning a foreign language. Consequently, the selection of reading passages in EFL textbooks is mainly directed toward the choice of what is comprehensible in addition to what is a step further than that level, as hypothesized by Krashen (Lightbown \& Spada, 2006).

The general agreement is that neither too difficult textbooks nor too easy ones help in second language acquisition. In fact, proficient reading is "an active process in which learners are capable of comprehending the text, produce hypotheses about the message of the text and then sample textual cues to confirm or reject those hypotheses" (Goodman, 1970, as cited in Clarke, 2000, p. 115).

Ur (2007) added the following characteristics of efficient reading:

- The language is comprehensible.

- The reading progresses fairly fast.

- The reader concentrates on the significant part and skips over unnecessary details.

- The reader thinks ahead, hypothesizes, and predicts what is coming next.

- The reader uses background information in order to understand the text.

- The reading is purposeful, and the reader is aware of the purpose of reading task.

Thus, reading skills are complicated as they involve "a great deal of precise knowledge which must be acquired or learned and many processing strategies which must be practiced until they are automatic" (Birch, 2002, p. 2).

Although it seems easy to improve students' comprehension of reading passages by adapting some pre-reading strategies or warm-up activities, it is not as easy as it seems here. Comprehension as stated by Grabe (2009) is 
rather a family of skills and activities. Transferring the author's main idea of the text into the brain of the reader is at the core of reading comprehension.

Why should teachers include reading comprehension in the EFL classroom? If Krashen's comprehensible input is to be considered a condition for learning, this probably could be introduced throughout listening to tracks and reading texts. As a result, English language skills are considerably influenced, leading to students' enriched vocabulary, improved grammatical knowledge, enhanced writing and spelling, among other possible advantages. Some reading texts help ESL learners understand the culture in English language context. Indeed, reading in the target language has enormous benefits regardless of the students' level of proficiency in the language as long as the two passive skills - reading and listening - provide comprehensible input.

According to constructivism, learning occurs when individuals integrate a new knowledge with a prior one (Tracey \& Morrow, 2006). Learners need to build schemata and make connections between new ideas and what they already have in their minds, which is known as schema theory. This theory describes the process by which readers combine their own background with the information in the text (Stott, 2001).

Therefore, according to schema theory, comprehending a text is an interactive process between the reader's background knowledge and the text. Efficient comprehension requires the ability to relate textual material to one's own background (Carrel \& Eisterhold, 2000).

In order to apply schema theory in the classroom, many choices are available, including the use of pictures, discussions, vocabulary pre-teaching, previewing and pre-questioning.

Harmer (2007) suggests another way of involving students: asking them to create their own comprehension tasks. In other words, the teacher encourages them to list things they know about a given topic, things they are not sure of, and finally things they would like to know more about. Such an activity will activate their schemata and motivate students to read and find out whether their pre-set ideas are correct or not.

These suggested pre-reading activities not only aim at activating the prior knowledge students already have, but also constructing relevant schemata.

However, Stott (2001) warns of taking care not to activate the prior knowledge at the expense of facilitating the foreign language learning, which might happen if the teacher overuses L1. He asserts that it is better for the teacher to introduce the new vocabulary and use L1 to access a student's prior knowledge in order to both activate prior knowledge and facilitate foreign language learning.

Tagliebar, Johnson, and Yarbrough (1988) argued that students of English as a foreign language usually find it difficult to comprehend English texts not only because they encounter unfamiliar vocabulary, but also because texts may contain unfamiliar concepts and cultural allusions. The students' inability to guess the meaning of new words or recognize the concepts and cultural allusions may result in serious comprehension impairment.

This issue has received abundant empirical support. Most studies have concluded that the utilization of pre-reading strategies in reading classes enhances comprehension regardless of the pre-reading strategy applied.

Yet previous research has also indicated that significant differences exist among different native language groups.

Carrel (1984), for instance, tried to investigate the effects of rhetorical organization on ESL readers from different backgrounds and different native languages. The study found that Arabic students - the population examined in the current study - performed differently from Spanish and Oriental groups. Thus, it is important to understand how differences in native language and culture affect the ultimate results.

There are considerable differences between Carrel's (1984) study and the present study in terms of the pre-reading strategies used. To the researcher's knowledge, no one has yet investigated the effectiveness of pre-reading strategies on the reading comprehension ability of Saudi EFL students, thereby indicating the need for the current study.

In addition, previous research has suggested that activating prior knowledge is effective for improving the reading comprehension ability of both L1 and L2 (i.e., EFL) teaching contexts. Recent research provides positive evidence for incorporating pre-questioning strategies and vocabulary pre-teaching, although the latter has not been that effective in facilitating reading comprehension. Hence-and in the light of such results - pre-questioning and vocabulary pre-teaching strategies serve as the focus in this study. In particular, this study tries to verify exactly which one is more effective in improving the reading comprehension ability of Saudi EFL college students. 


\subsection{Question of the Study}

The current study aims to investigate the effects of two pre-reading strategies on Saudi EFL college students' performance in reading comprehension by answering the following question:

Are there any significant differences in Saudi EFL college students' performance in reading comprehension due to the pre-reading strategy used (i.e., vocabulary pre-teaching versus pre-questioning strategy?

\subsection{Objective of the Study}

Due to research findings regarding the use of pre-reading strategies in reading classes, the current study seeks to identify how these strategies can be used to facilitate reading comprehension. Learners of English as a foreign language usually experience certain difficulties because of their lack of vocabulary or unfamiliarity with some conceptual issues (Tagliebar et al., 1988). The use of pre-reading strategies in reading classes can provide students with the meaning of key words while other strategies help motivate students to read the passage. The current study investigates whether pre-questioning is more effective than vocabulary pre-teaching for Saudi EFL college students.

\subsection{Significance of the Study}

Since reading is one key area in EFL teaching, this study draws teachers' attention to some pre-reading activities that should be used before reading begins in reading lessons. It also provides EFL teachers with an example of how to use two pre-reading strategies (i.e., vocabulary pre-teaching and pre-questioning). Furthermore, it will help identify which one of the two strategies examined is more effective.

\section{Literature Review}

An increasing amount of educational research has been dedicated to examining the extent to which pre-reading activities affect students' performance in reading comprehension. As this issue has been empirically proven to be helpful, attention has more recently shifted to investigating which of the pre-reading activities is more effective in facilitating comprehension.

Johnson (1980, as cited in Chang, 1990) investigated the effects of vocabulary and background knowledge on students' comprehension. Seventy-two university-level ESL students participated in their study. The results indicated that content schemata are more effective for enhancing students' comprehension than form schemata. To sum up, regardless of the kind of schemata being activated, it advances the students' performance.

Chang (1990) concluded that it mainly depends on the readers' proficiency rather than the kind of schemata being addressed. Unlike beginner readers, more proficient ones come to read the text with a special question in mind. In other words, they approach reading text with a top-down strategy.

Carrel (1984) conducted a study to examine the effects of the rhetorical organization of different types of expository prose on intermediate ESL readers of different native languages. In the study, 80 students were divided into 3 native language groups: Spanish, Arabic, and Oriental. The study tried to depict the differences among the four types of rhetorical organization of expository text (comparison, causation, problem/solution, and collection of descriptions) in the reading recalls of ESL readers as well as identify differences among various native language groups. The participants were asked to read the passages; two written recalls were then administered — one immediately after reading the passage and the other 48 hours later. Participants were asked to write down everything they could remember from the text using their own words. They were also asked to write down how ideas were connected to each other. Results indicated significant differences among the four types of rhetorical organization of expository prose on the reading recalls of ESL readers. In addition, significant differences emerged among the three native language groups .To sum up, the more highly organized types of discourse (comparison, problem/solution, causation) are generally more facilitative of recall than the less organized collection of description.

The results also revealed that the various discourse types had different effects for different language groups. The study concluded that if ESL readers - regardless of their native language background-possess the formal schemata against which to process the more highly structured types of organization, then encoding, retention, and retrieval are generally facilitated as well.

Taglieber et al. (1988) dealt with effects of three pre-reading strategies that seemed most practical for EFL learners: pictorial context, vocabulary pre-teaching, and pre-questioning. The study investigated the effectiveness of previous pre-reading strategies among 40 Brazilian undergraduate EFL students. All participants read four different passages, reading each passage under one of the four conditions. Participants then answered questions. The results indicated that pre-reading activities produced significantly higher multiple choice scores than the 
control condition. It is worth noting that vocabulary pre-teaching resulted in increased comprehension compared with the control group, but it was less effective than the other two strategies. The researchers concluded that results were in full agreement with what theorists in L1 have suggested as they argued that providing students with some assistance before reading can help them understand a text. However, vocabulary pre-teaching was not as effective, and the researchers argued that-for the other two pre-reading activities (i.e., pictorial context and pre-questioning) - heightened background knowledge made students more able to use the context to arrive at a satisfactory meaning for the given passage even if they did not know the meaning of all the new words in the passage. To justify the limited effect of vocabulary pre-teaching, the researchers argued that words were not connected to the content of the reading passage. In addition, students did not seem interested in discussing scattered words; this activity did not result in active involvement of the students.

With special reference to rhetorical patterns of texts, but with a much larger sample than Carrel's (1988) study, Sharp (2002) conducted a similar study to measure the comprehension of 440 Hong Kong Chinese school children studying English in order to investigate the effects of different texts on students. Similar to Carrel's study, Sharpe's results indicated differences in comprehension between texts types. The researcher concluded that increasing awareness of rhetorical patterns would be beneficial for EFL students.

Zhaohua (2004) conducted a similar study to identify effects of previewing and providing background knowledge on reading comprehension of EFL students working with American documentary narratives. Seventy-eight non-English major students attending the agriculture college of Yangzhou University in China participated in that study. The results revealed that the background knowledge group had superior performance over the control group. However, there was no difference in participants' performance between the preview group and the control one.

Alemi and Ebadi (2010) examined the effects of pre-reading activities among 40 undergraduate engineering students' ESP reading comprehension. The students were divided into two groups: experimental and control. The experimental group received a treatment employing the three pre-reading activities: pictorial context, vocabulary pre-teaching, and pre-questioning. The experimental group demonstrated more considerable abilities in comprehension than the control group. Thus, the authors concluded that the employment of pre-reading activities would improve students' reading comprehension abilities.

Yusuf (2011) investigated the effect of pre-reading activities on ESL students' reading comprehension in a senior secondary school. Fifty students from two secondary schools in Kaduna (Nigeria) participated. The experimental group was exposed to pre-reading activities - namely, previewing, pre-reading discussion, and brainstorming, whereas the control group was taught using traditional methods. The results indicated that the experimental group performed better than the control group. The researcher recommended the use of these pre-reading activities and added they might serve as useful tools for language - particularly for reading teachers - in facilitating learners' reading comprehension ability.

A similar study was conducted by Mihara (2011), who investigated the effects of two pre-reading strategies: vocabulary pre-teaching and comprehension question presentation. Mihara also verified whether lower-level students outperform higher-level students if the former were provided with a more effective strategy to use. Participants included 78 Japanese university students. The results indicated that vocabulary pre-teaching is less effective for Japanese students. Furthermore, students with higher English proficiency outperformed lower-level students regardless of the pre-reading strategy used.

Mihara pointed out that EFL students feel satisfied if they are taught vocabulary before reading a passage, although the study results suggest that vocabulary is not as effective as they think.

In a similar context, Maghsoudi (2012) also advocated the activation of schema through the use of some pre-reading activities.It is worth noting that the reader role has shifted from passive to more interactive according to Carter and Nunan (2002, as cited in Maghsoudi, 2012). It used to be classified as one of the passive skills together with listening, but it helps make the reader become more involved with the text. Maghsoudi emphasized the use of pre-reading activity especially for culturally burdened texts to facilitate the combination of what readers already know and what is new to them. Her sample was composed of 76 undergraduate Iranian EFL students. They were divided into experimental and control groups. The former was trained through previewing, pictorial text, and the pre-teaching of vocabulary whereas the latter was not exposed to any particular treatment.The results indicated that the experimental group students outperformed the control group students. Consequently, the current study also ensures that students' comprehension ability can be enhanced if the schema is activated. 
As these studies indicate, pre-reading activities have been examined in a variety of contexts in both the EFL and native language fields. Indeed, the use of pre-reading activities has received abundant empirical support in various EFL contexts.

\subsection{Theoretical Framework}

\subsubsection{Schema Theory: Prior Knowledge and Comprehension}

Schema refers to cognitive constructs that allow for the organization of information in long-term memory (Widdowson, 1983 as cited in Singhal, 1998). Wilson and Anderson (1986) provided a simpler definition: Schema refers to the process by which pre-existent knowledge affects comprehension. While reading a text or listening to a narrative, our comprehension is usually guided by our existing knowledge, which can possibly affect our understanding of the text. For example, prior knowledge may help understand the new vocabulary of the text (Carpenter \& Just, 1986). Thus, schema is the process by which a reader combines his or her background knowledge with what is mentioned in the text (Stott, 2001) to facilitate comprehension. Therefore, it can be used to explain how prior knowledge brings about better understanding.

As stated earlier, prior knowledge affects comprehension enormously. Wilson and Anderson (1986) argued that a message can be easily comprehended if the reader is able to activate or construct a schema; this can happen only if the schema gives a good account of the objects and events described. According to different classifications of schemata, prior knowledge, as explained by Carpenter and Just (1986), provides "a preexisting framework that the reader can use to assimilate new information" (p. 18). Therefore, decisions could be easily made on what is important in the text and what is not. Readers are also more likely to remember what they have read if their prior knowledge is effectively activated. Bruner (1960, as cited in Wilson \& Anderson, 1986) and Ausebel discussed the significance of two aspects of schemata: activity and organization. Bruner identified that the key to knowledge was active integration of old and new information. In other words, based on previous knowledge, information gaps could be filled. Ausebel, meanwhile, argued that knowledge is organized in a certain way in which abstract ideas are the most general ones. For him, providing students with a short introduction to the text is of great importance. He also suggested that an "advanced organizer" is essential for helping students fill in the gaps between their prior knowledge and new information. An advanced organizer is the abstract structure students need to assimilate the more detailed information that follows.

To understand how prior knowledge aids comprehension, it is important to understand how comprehension develops. Comprehension usually results from recollected feelings called up by a sequence of words, phrases, and sentences (Huey, 1908, as cited in Wilson \& Anderson, 1986). It is essential in reading classes not to concentrate only on relating past experiences of students to the new information they encounter in the text. Rather, the teacher should ask students to make predictions about incoming text. These predictions are usually drawn on the students' prior knowledge. This approach - first suggested by Stauffer (1969, as cited in Wilson \& Anderson, 1986) - is called directed reading thinking and is an example of pre-reading strategies.

For example, schemata are individualized and changing (Tracey \& Morrow, 2006). Everyone's schemata differ from others' due to individuals' areas of interest and experiences. The changeability characteristic of schemata helps individuals reshape and refine their schemata based on the individuals' experiences. Wilson and Anderson (1986) classified schemata into:

1) Text-structure schemata (i.e., formal schemata that refer to knowledge about discourse level forms); and

2) Content schemata (i.e., substance conveyed in the text).

Similarly, Stott (2001) distinguished between content and formal schemata; the former means background knowledge of the world whereas the latter means background knowledge of rhetorical structure.

For nonnative readers, some content schema does not exist; as a result, readers cannot achieve a reasonable overall understanding. Many factors come into play in such a situation, including the lack of some conceptual knowledge. At other times, the same concepts have other possible interpretations in the native language of readers, which can also lead to misunderstanding (Stott, 2001).

\subsubsection{Reading}

According to Goodman (2000), two opposite views in literature explain what reading is. The first one refers to matching sounds to letters, whereas the other one refers to ambiguity of how reading works. Thus, a distinct difference exists between reading in its early stages, when involves decoding letters into sounds, and reading in its interactive form, when the reader receives the language of a given text and transfers it into thoughts. Consequently, key assumptions perceive reading as a guessing game or hypothesis testing (draft and revision) in 
which the reader makes some guesses in the former and tests them later on or-in the latter assumption - the reader arrives at a conclusion after revising initial hypotheses. Regardless of the assumption, readers have to have adequate background knowledge (Alyousef, 2005). Therefore, reading is best defined as a receptive language process (Goodman, 2000). Goodman also thinks that it is a psycholinguistic process that starts with "a linguistic surface representation encoded by a writer and ends with meaning which the reader constructs" (p. 11).

Reading is an interactive process between the text and the reader. Moreover, reading itself is a complex process for which the brain employs the following processes, as listed by Goodman (2000):

1) Recognition-initiation: The brain recognizes a graphic display in the visual field as written language and initiates reading.

2) Prediction: The brain is predicting and seeks order and significance in sensory input.

3) Confirmation: With subsequent input, the brain tries to confirm or reject what it expects.

4) Correction: The brain reprocesses when it finds incorrect predictions.

5) Termination: This stage comes when the reading task is completed. It may also occur when the reader thinks the task is nonproductive, or when the content is already known.

Thus, clearly reading is not an easy task. Many factors contribute to poor comprehension. Taglieber et al. (1988) listed the main sources of difficulty in reading that EFL students usually encounter-namely, a lack of vocabulary knowledge and a lack of conceptual knowledge and cultural allusions. Thus, if EFL learners are not prepared with conceptual and cultural allusions in addition to the ability to use some skills related to vocabulary, their comprehension may be impaired.

\subsubsection{Pre-Reading Strategies}

The use of pre-reading activities in EFL reading classes reflects course designers' attempts to activate schemata and make use of students' prior knowledge to facilitate comprehension. Many textbooks for EFL learners provide plenty of pre-reading strategies, yet others do not have this essential component of reading. If the latter is the case, it is highly recommended for the teacher to create his or her own strategies and diversify activities according to students' performance in reading. Several different options are available, including pre-questioning, vocabulary pre-teaching, previewing, advanced organizers, and pictorial context. The first two examples - pre-questioning and vocabulary pre-teaching - are discussed in further detail here.

The pre-questioning strategy is best defined as an introduction of a summary that echoes the text content, about which both the teacher and students start asking some questions, guessing answers, and —above all—drawing some inferences before reading begins.

Once the topic is introduced, students must start to activate previous knowledge about that topic (i.e., schemata). For instance, if the topic Nigerian transportation is introduced, students start building on their previous information about Nigeria. Before they read, they would be likely to guess what kinds of transportation Nigerians have and what problems might arise from such transportation. Pre-questioning is a conventional type of pre-reading strategy that focuses on brainstorming and idea formation about the incoming text. As such, it is the most common strategy adopted by foreign language teachers. Nuttal (1982, as cited in Alemi \& Ebadi, 2010) suggested that signpost questions would be of great help in pre-questioning. However, it is important to understand that the questions a teacher asks before reading begins are not asked to test students' comprehension; rather, they should pique students' curiosity to check whether their predictions are correct or not.

Ur (2007, p. 145) added that students "probably feel more motivated to read, and reading itself was more purposeful, because of the challenge of finding out whether [they] had got [their] answers right or not." Carefulness in preparing questions in advance of reading, on the part of the teacher, helps achieve the goals of such a strategy.

Another strategy commonly used is vocabulary pre-teaching, including the use of flash cards, pictures, translation, or the demonstration of new vocabulary. Learning vocabulary does not merely mean the ability to define a word's meaning. Students also need to know other relevant details, including pronunciation, part of speech, spelling, and - most importantly - how to use the word in a proper sentence. Students need to see words in context to see how they are used (Harmer, 2007). In this respect Ellis (in Ellis, 2009) pointed out that vocabulary is not necessarily learned word by word. Rather, "lexical acquisition takes place through the process of segmentation" (p. 99). If the emphasis is on the ability to use words in different contexts and in different structures, the word is truly acquired. 
In terms of the improvement of students' comprehension, Folse (2004, as cited in Hedgecock \& Ferris, 2009) noted that L2 learners quickly discover that their lack of vocabulary knowledge results in serious comprehension problems. Thus, EFL students feel secure when they know the meaning of new words before reading begins. From students' perspective, knowing the meaning of every word in a given text is essential. Nation (2001, as cited in Hedgecock \& Ferris, 2009) stated that "Direct teaching can add to incidental learning of the same words and can increase learners' awareness of particular words so they notice them" (p. 295). Although some (e.g., Mihara, 2011; Taglieber et al., 1988) have asserted that direct vocabulary teaching does not prove to be effective in facilitating reading comprehension, combining contextual and definitional support produces better comprehension and vocabulary learning than methods alone (Stahl \& Fairbanks, 1986, as cited in Hedgcock \& Ferris, 2009). Ultimately, vocabulary pre-teaching can help students understand difficult key words of incoming text before they start reading.

\subsubsection{Saudi EFL Context}

Students in Saudi Arabia start studying English in intermediate schools. It is only recently that they have started studying English at grade four in primary school.

Unlike public school, students in private schools start studying English at an earlier age in first primary grade.

Grammar-translation method is considered the most common method adopted to teach English in Saudi Arabia, and this is due to the style of textbooks the ministry of education has used. Since grammar-translation method stresses translation of new words, students are used to working with translation and that explains their desire to understand the meaning of every word they encounter in texts. Such a method does not suggest the employment of some skills to overcome their lack of new words knowledge.

Fortunately, the communicative language teaching is introduced in EFL field during the last years as new package of modern textbooks have been agreed upon for primary, intermediate and secondary schools.

\section{Research Design}

Despite the positive evidence of the effectiveness of pre-reading strategies in L2 reading comprehension, no previous study has verified whether such pre-reading strategies have the same effect on Saudi EFL learners. Therefore, the current study investigates whether the pre-questioning strategy helps improve comprehension more than vocabulary pre-teaching for Saudi EFL college students.

The researcher used a quasi-experimental design in which two different treatments were introduced to two equivalent groups of students. The use of a control group in addition to random sampling and distribution of participants are the three main conditions for a true experiment (Ellis, 2009). Because of the purposeful sampling but the absence of a control group, this study is quasi-experimental, focusing on one independent variable: pre-reading strategies, which are divided into vocabulary pre-teaching and pre-questioning. The dependent variable is students' reading comprehension performance. The first group was randomly chosen to be exposed to the vocabulary pre-teaching strategy and the other group was introduced to the pre-questioning strategy. In the present study, no control group was used due to previous studies' assertions that pre-reading strategies are effective for enhancing reading comprehension. Indeed, it was of greater importance to compare the two pre-reading strategies and determine which one is more effective for Saudi EFL students.

\subsection{Study Hypothesis}

The hypothesis tested in the current study is: Statistically significant differences $(\alpha \leq .05$ exist among Saudi EFL college students' performance in reading comprehension according to the pre-reading strategy (vocabulary pre-teaching versus pre-questioning strategy), with the pre-questioning group showing greater comprehension.

\subsection{Variables}

The study has one dependent variable: students' performance in reading comprehension. This variable is assessed using four reading comprehension tests at the end of each reading selection; the students had to choose the correct answer among three choices for each question. These tests were graded and corrected to process the results using SPSS software. Meanwhile, the independent variable is pre-reading strategies, which include (a) vocabulary pre-teaching and (b) pre-questioning.

\subsection{Participants}

A purposeful sample composed of 46 second-semester female EFL students in their preparatory year at King Saud University, Saudi Arabia, was chosen to participate in the study. They were selected randomly from a group of sections who had already finished level 5 in preparatory year of Medical and Applied Sciences. Half (23) of the students were randomly assigned to the first experimental group, which was exposed to the vocabulary 
pre-teaching strategy whereas the other half (23) of the students were introduced to the pre-questioning strategy (see Table 1). All students' native language was Arabic; participants' ages varied from 19 to 20.

Table 1. Distribution of participants

\begin{tabular}{ll}
\hline Pre-Questioning & Vocabulary Pre-Teaching \\
\hline 23 students & 23 students Students \\
\hline
\end{tabular}

Because students who attend King Saud University are not the same in terms of their English language proficiency as some are at advanced level and others are at an intermediate level, students are required to take a placement test and then divided into appropriate levels. The participants in this study were enrolled in level 6; their English level is at Band 6 in terms of the International English Language Testing System (IELTS). They study the four English skills for approximately 17 hours each week, and English classes are compulsory for all students in the preparatory year. As the experiment for the current study was carried out over four days, some students were unable to attend all the reading lectures, meaning they could not complete the comprehension test. This situation was taken into consideration when analyzing the data.

\subsection{Materials}

In order to check the effectiveness of pre-reading strategies on students' performance in reading comprehension, four reading passages ranging in length between 470 and 504 words were carefully selected for use in reading classes. The passages, together with their comprehension questions, were taken from More Reading Power by Beatrice S. Mikulecky and Linda Jeffries. The titles of the passages were: "Maria Montessori, her childhood and her university life"; "A thirsty planet," and "Nigerian style of transportation." They were intentionally chosen to be of general interest and appropriate to students' language proficiency level. They were neither ambiguous nor showed any conceptual difficulty. They were also the same in terms of prior content familiarity.

\subsection{Instrumentations}

In order to test students' comprehension of the passages, they had to answer eight multiple choice questions after each passage. They were not required to answer using their own words; instead, three choices were provided for each question. Some of these questions were direct (e.g., asking about the main theme of the passage, as clearly shown in the title), although the three choices provided were not as clear. For example:

\section{1-This passage is about:}

a. pollution problems.

b. an industrial site in Missouri.

c. groundwater pollution.

Other questions urged students to make inferences in order to guess at the answers:

\section{8-You can understand from this passage that}

a. Maria was not famous.

b. Maria's life was ordinary

c. Italian women generally did not speak in public.

To ensure the tests' reliability, a Cronbach's alpha was computed for the four tests (see Table 2). The results varied from .62 to .66 . These results indicated that the internal consistency of the four tests were high.

Table 2. Reliability statistics

\begin{tabular}{llll}
\hline & Number of items & Alpha Cronbach & Significance \\
\hline Test one & 8 & .66 & Significant at 0.01 \\
Test two & 8 & .63 & Significant at 0.01 \\
Test three & 8 & .62 & Significant at 0.01 \\
Test four & 8 & .62 & Significant at 0.01 \\
\hline
\end{tabular}




\subsection{Procedures}

The researcher used one of the quasi-experimental designs in which two different treatments were introduced to two groups - namely, (a) vocabulary pre-teaching and (b) pre-questioning. Because the effectiveness of pre-reading strategies has generally been empirically proven, there was no need to have a control group. Instead, the attention focused on verifying whether one of pre-reading strategies was more effective than the other.

Participants were randomly assigned to the two groups. However, they were not required to perform a pre-test. The researcher did not believe that participants needed to be tested to establish homogeneity because students were distributed into levels according to their proficiency test results taken prior to enrolling in Preparatory Year at the university. The treatment consisted of one pre-reading strategy, which was randomly assigned to each group.

The first experimental group was introduced to the vocabulary pre-teaching strategy. On the days of the experiment, students were introduced to the new passage. The researcher read the title and then provided a short introduction about the topic in order to familiarize students with the content. Next, she asked them to look at a list of new vocabulary attached to the passage and comprehension questions. The researcher along with the students translated the new vocabulary and phrases into Arabic. In some cases, students asked for synonyms, which were provided. At other times, students came up with synonyms themselves. Interestingly, they asked the researcher about certain logical connections that they had made between the words and the title of the passage, suggesting that they had already become actively involved in the text.Such translation process lasted for Ten minutes. The researcher asked participants to read the passage and answer comprehension questions. Participants had an additional 10 minutes to answer the 8 comprehension questions.

The second experimental group used a pre-questioning strategy. On the days of experiment, students were given a one-sentence summary of the passage content. The researcher together with participants started to ask some related questions; the participants were not sure of the answers. Participants were provided with paper to write any ideas and questions that came to mind. An important goal of this phase was to urge students to make inferences built upon their previous knowledge. Such an activity stirred up students' motivation to read the given texts. For example, when the researcher introduced the topic of Maria Montessori's childhood, students knew nothing but her educator identity due to the appearance of her name on several private school boards. When participants learned that she was the first female doctor, they were curious to read more and find out about her life story.

After raising several important questions, participants were given 10 minutes to read the passage and answer the 8 comprehension questions.

Papers were then corrected. Each question was given one mark. Students' scores on reading comprehension questions were considered the dependent variable for the current study. The independent variable was the pre-reading strategies used in the two groups.

Means, standard deviations, and $t$-tests were then calculated to analyze the data and examine the significance of differences in the two groups' reading comprehension scores.

\section{Results}

Are there significant differences in Saudi EFL college students' performance in reading comprehension if they received different pre-reading strategies (i.e., vocabulary pre-teaching vs. pre-questioning)? To answer this question, means and standard deviations for the students' reading comprehension scores were calculated as shown in Table 3.

Table 3. Means and standard deviations of students' reading comprehension scores

\begin{tabular}{llllll}
\hline & Group & $\mathrm{N}$ & Mean & Std. Deviation & Std. Error Mean \\
\hline \multirow{2}{*}{ total_1 } & Vocabulary pre-teaching & 23 & 6.3370 & .89594 & .18682 \\
& Pre-questioning & 23 & 5.8913 & .91406 & .19059 \\
\hline
\end{tabular}

*Means are out of 8 .

Table 3 shows that there are observed differences between the means of the students' scores according to the pre-reading strategy. 
The mean of vocabulary pre-teaching group is 6.33 out of 8 , with a standard deviation of .89 , whereas the mean of the pre-questioning group is 5.8, with a standard deviation of .91. The means of the two groups are close. In order to verify whether there are significant differences between the two groups at the 0.05 significance level, a $t$-test of the two independent samples was used (see Table 4).

Table 4. Results of t-test of students' reading comprehension scores

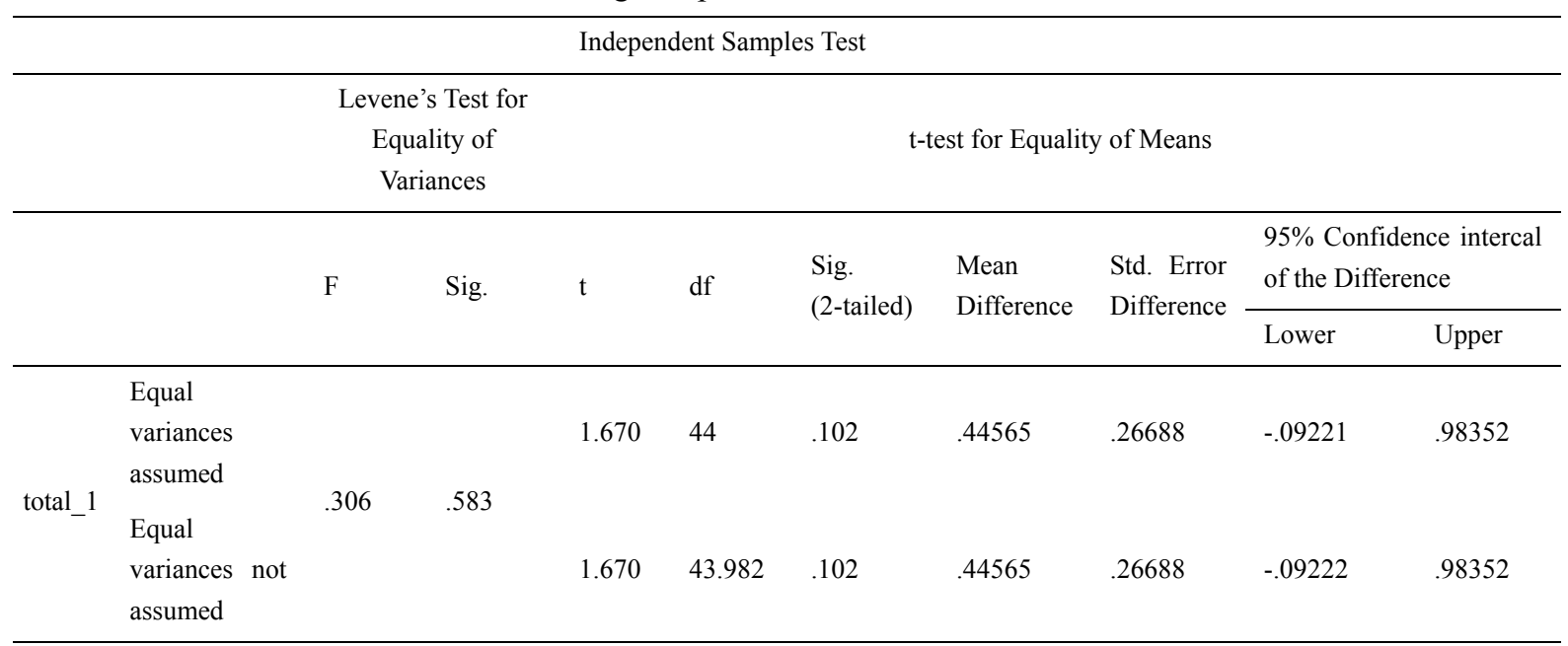

*Significant at 0.05

Table 4 shows that the $t$ value is 1.67 , which is significant at .102 . Based on this result, the null hypothesis is accepted:

There are no statistically significant differences at $(\alpha \leq .05$ in Saudi EFL college students' performance in reading comprehension due to the pre-reading strategies (vocabulary pre-teaching vs. pre-questioning).

This contradicts previous results with other samples. It was expected that the pre-questioning group would perform better on the comprehension test than the vocabulary pre-teaching group. In particular, this finding is inconsistent with Mihara (2011) and Taglieber et al. (1988), who found that the pre-questioning strategy helps students' comprehension better than vocabulary pre-teaching strategy.

\section{Discussion}

Pre-reading strategies, in general, improve students' comprehension of texts (e.g., Zhaohua, 2004) because pre-reading strategies activate students' prior knowledge (Chang, 1990; Maghsoudi, 2012). Mihara's (2011) and Taglieber et al.'s (1988) findings advocated the use of pre-reading strategies. They found that students who use pre-questioning comprehend better than those who use vocabulary pre-teaching.

The study finding provided empirical answer to the study question posed. In addition, it asserted the employment of pre-reading strategies in reading lessons not only for facilitating reading comprehension by activating prior knowledge, but also as an effective activity to stimulate students' motivation in reading classes. Motivation plays an important role in foreign language learning (Ur, 2007)

However, in the present study, a null hypothesis is accepted based on the $t$-test value. In contrast to previous research results, the pre-questioning group did not perform better than the vocabulary pre-teaching group. Such an unexpected result of the study could be attributed to many reasons:

1) Unlike native and skilled readers, EFL students, in general, like to know the meaning of each word they encounter in a text. They do not skip over unknown words. Taglieber et al. (1988) claimed that EFL students' lack of vocabulary knowledge causes comprehension problems. Thus, providing students with the meaning of key words seems to be a solution for one of the main causes of comprehension problems. For Saudi EFL students, it seems to be equal in its effectiveness to pre-questioning strategy as it becomes a key to understanding the passage - at least from students' point of view especially if they are used to working with a translation method.

2) Although the vocabulary pre-teaching strategy was supposed to be less effective than pre-questioning strategy, the researcher's observations during the data collection process revealed that both vocabulary pre-teaching and 
pre-questioning groups were fully involved in the pre-reading stage. Participants in the vocabulary pre-teaching group did not receive the translation passively; they asked about synonyms and predicted meaningful connections to the title of the passage.

3) It is worth noting that the new words on the translation sheet were arranged in the same order in which they appeared in the text, making it easy to pick up the meaning of any word not understood in the text from the list provided. Although knowing the meaning of the word does not necessarily mean that learners can use it, this approach at least made it easier for the vocabulary pre-teaching group to understand key ideas in the text.

4) The pre-questioning group did not outperform vocabulary pre-teaching group as expected. One possible justification for this unexpected result is that the pre-questioning group's activated background information knowledge was not sufficient. As such, the prior information the researcher tried to activate before reading began was not sufficient to form a meaningful perception upon which upcoming information would be built.

To summarize, the two groups demonstrated the same comprehension performance on the tests, which was totally contrary to the expected results. The researcher identified possible reasons for such a result, but regardless, the employment of pre-reading strategies remains beneficial for preparing students for incoming tasks and is helpful as a motivating factor that affects reading comprehension considerably.

\subsection{Contribution \& Implications}

Drawing on the results of the study, the researcher suggests the following recommendations:

For EFL Teachers:

1) Many pre-reading strategies can be used to familiarize students with the text context and improve their comprehension, including pre-questioning, vocabulary pre-teaching, asking students to write their own questions and answer them, and suggesting vocabulary that they might encounter.

2) Students do not need to understand the meaning of every single word in the text. It is the teacher's responsibility to train students to try guessing the meaning or skipping over some words. Comprehension skills must be emphasized more in reading classes.

For Syllabus Designers:

1) To ensure that reading passages provide comprehensible input that helps in learning a foreign language, reading selections of a given level should be carefully chosen to be neither too difficult nor too easy.

2) Introducing reading passages in EFL textbooks with some pre-reading strategies would add to the effectiveness of reading comprehension classes. In addition to motivating students to read the texts, they improve reading process, as has been empirically proven.

For Researchers:

1) Further research is needed to investigate the effectiveness of other pre-reading strategies in the Saudi EFL context.

\subsection{Limitations}

This study was limited to female undergraduate students at King Saud University in Saudi Arabia. It was also limited to the academic year 1432/1433 (2011/2012). The study findings cannot be over generalized because the instrumentations were objective in nature (i.e., multiple choice questions), suggesting there were high chances of guessing the answers.

\section{Conclusion}

If EFL teachers are to facilitate reading comprehension in reading classes, then the employment of pre-reading strategies is highly recommended. Reading skills have an ambiguous nature as educators know little about how this process occurs. Nevertheless, the two processes that reading involves are decoding letters into sounds (in earlier stages) and the process by which the thoughts of the writer are correctly transferred into the reader's mind. Reading is an essential part of the process of learning English as a foreign language, but it is not an easy process. Significant efforts are needed to achieve satisfactory results in teaching a specific course of reading. An example of these efforts is the use of pre-reading strategies to enhance the reading comprehension process. Comprehensible input is not the area of focus in the present study, although it is an important condition for learning to happen. Rather, the researcher shed light on the pre-reading activities that teachers together with students can practice before reading begins. Such strategies help access students' prior knowledge and activate it throughout the introduction of new words or engaging questions. 
Schema theory provides theoretical support for the use of such strategies in classes, which do not merely aim at activating prior knowledge, but also help construct relevant schemata. In that way, pre-reading strategies make reading comprehension easier, as the existing large body of research has demonstrated. Thus, it is of great importance to identify which strategies are most effective in the Saudi EFL context. The researcher compared two pre-reading strategies (pre-questioning and vocabulary pre-teaching) by collecting data among female Saudi college students at King Saud University; the analysis indicated that these two strategies were the same in their effectiveness, which was unexpected and not consistent with previous studies' results.

Such unexpected findings might stem from the total involvement of the vocabulary pre-teaching group during the pre-reading strategies, although both groups were curious to know more about topics and showed strong motivation. Clearly, the strategies stimulated students' motivation to read and find out what the passage is about. In the vocabulary pre-teaching group, new words were translated into Arabic so that students would not focus on having to guess the meaning; however, in most cases, they asked and gave synonyms in English.

In addition, they predicted some meaningful connections between words and titles of passages, indicating that they were paying attention and trying to relate their prior knowledge to the new information in the form of some meaningful predictions they gave. The new words were arranged in the same order they appeared in the passage, which made it possible for students to find the meaning of difficult words as they proceeded in reading process.

To conclude, the study emphasized the importance of pre-reading strategies in EFL reading lessons. They affect students' performance in reading considerably. They are also beneficial in terms of motivating students to read. Thus, it is highly recommended that EFL teachers use such pre-reading strategies in reading lessons.

With special reference to the fact that the adaptation of pre-reading strategies improves students' reading comprehension, the present study provides empirical support from Saudi Arabia that the pre-questioning strategy affects students' comprehension in the same way as the vocabulary pre-teaching strategy.

\section{Acknowledgements}

First and foremost, Praise be to Allah, who inspired me with patience to finish this work. With lots of love, this work is dedicated to: My mother, who has given endless support throughout my life, My husband and my little kids, who dealt with all my absence with a smile, My brothers, who have always stood by me and believed that I could do it and to the rest of my family, who were encouraging all the time.

It is with immense gratitude that I acknowledge the support and help of my supervisor Dr. Hind Al-Fadda. Without her guidance and persistent help, this work would not have been possible.

I am also indebted to professor Abdallah Bani Abdulrahman for facilitating the data collection process in the Preparatory Year at King Saud University.

\section{References}

Alemi, M., \& Ebadi, S. (2010). The effects of pre-reading activities on ESP reading comprehension. Journal of Language Teaching and Research, 1(5), 569-577. Retrieved from http://www.academia.edu/277588/The Effects_of_Pre-reading_Activities_on_ESP_Reading_Comprehension

Alyousef, H. (2005). Teaching reading comprehension to ESL/EFL learners. The Reading Matrix, 5(2), 143-154. Retrieved from http://www.readingmatrix.com/articles/alyousef/article.pdf

Birch, B. M. (2002). English language reading: Getting to the bottom. Mahwan, NJ: Lawrence Erlbaum Association.

Carpenter, P. A., \& Just, M. A. (1986). Cognitive processes in reading. In J. Orasanu (Ed.), Reading comprehension from research to practice (pp. 11-30). Hillsdale, NJ: Lawrence Erlbaum Associates.

Carrell, P. L. (1984). The effects of rhetorical organization on ESL readers. TESOL Quarterly, 18(3), 441-469. http://dx.doi.org/10.2307/3586714

Carrell, P. L., \& Eisterhold, J. C. (2000). Schema theory and ESL reading pedagogy. In P. L. Carrell, J. Devine, $\&$ D. Eskey (Eds.), Interactive approaches to second language reading (pp. 73-92). Cambridge: Cambridge University Press.

Chang, Y. (1990). Schema theory and ESL reading (Master's thesis). Available from ProQuest, UMI Dissertations Publishing (No. 1342221).

Clarke, M. A. (2000). The short circuit: Hypothesis of ESL reading or when language competence interferes with reading performance. In P. L. Carrell, J. Devine, \& D. Eskey (Eds.), Interactive approaches to second language reading (pp. 114-124). Cambridge: Cambridge University Press. 
Ellis, R. (2009). The study of second language acquisition. Oxford: Oxford University Press.

Goodman, K. (2000). The reading process. In P. L. Carrell, J. Devine, \& D. Eskey (Eds.), Interactive approaches to second language reading (pp. 11-21). Cambridge: Cambridge University Press.

Grabe, W. (2009). Reading in a second language: Moving from theory to practice. Cambridge: Cambridge University Press. http://dx.doi.org/10.1017/CBO9781139150484

Harmer, J. (2007). The practice of English language teaching. Essex, England: Pearson Education Limited.

Hedgecock, J., \& Ferris, D. R. (2009). Teaching readers of English: Students, textsand contexts. New York: Routledge.

Lightbown, P., \& Spada, N. (2006). How languages are learned. Oxford: Oxford University Press.

Moghsoudi, N. (2012). The impact of schema activation on reading comprehension of cultural texts. Canadian Social Sciences, 8(5), 196-201. Retrieved from http://www.cscanada.net/index.php/css/article/view/j.css. 1923669720120805.3131

Mihara, K. (2011). Effects of pre-reading strategies on EFL/ ESL reading comprehension. TESL Canada Journal, 28(2), 51-73. Retrieved from http://www.teslcanadajournal.ca/index.php/tesl/article/view/1072

Sharp, A. (2002). Chinese L1 schoolchildren reading in English: The effects of rhetorical patterns. Reading in a Foreign Language, 14(2), 111-135. Retrieved from http://nflrc.hawaii.edu/rfl/October2002/sharp/sharp.html

Singhal, M. (1998). L1 and L2 reading A comparison of: Cultural differences and schema. Internet TESL Journal, 10(IV). Retrieved from http://iteslj.org/Articles/Singhal-ReadingL1L2.html

Stott, N. (2001). Helping ESL students become better readers: Schema theory application and limitation. Internet TESL Journal, 11(VII). Retrieved from http://iteslj.org/Articles/Stott-Schema.html

Taglieber, L. K., Johnson, L. L., \& Yarbrough, D. B. (1988). Effects of preceding activities on EFL reading by Brazilian college students. TESOL Quarterly, 22(3), 455-471. http://dx.doi.org/10.2307/3587289

Tracey, D., \& Morrow, L. (2006). Lenses on reading: An introduction to theories andmodels. New York: Gulf Press.

Ur, P. (2007). A course in language teaching practice \& theory. Cambridge: Cambridge University Press.

Wilson, P. T., \& Anderson, R. C. (1986). What they don't know will hurt them: The role of prior knowledge in comprehension. In J. Orasanu (Ed.), Reading comprehension from research to practice (pp. 31-48). Hillsdale, NJ: Lawrence Erlbaum Associates.

Yusuf, H. O. (2011). The effect of pre-reading activities on students' performance in reading comprehension in senior secondary schools. Educational Research, 2(9), 1451-1455. Retrieved from http://connection.ebscohost.com/c/articles/67708870/effect-pre-reading-activities-students-performance-rea ding-comprehension-senior-secondary-schools

Zhaohua, S. (2004). Effects of previewing and providing background knowledge on EFL reading comprehension of American documentary narratives. TESL Reporter, 37(2), 50-63. Retrieved from https://journals.lib.byu.edu/spc/index.php/TESL/article/download/32548/30708

\section{Copyrights}

Copyright for this article is retained by the author(s), with first publication rights granted to the journal.

This is an open-access article distributed under the terms and conditions of the Creative Commons Attribution license (http://creativecommons.org/licenses/by/3.0/). 